\title{
Idiopathic Thrombocytopenic Purpura (ITP): A Case Report
}

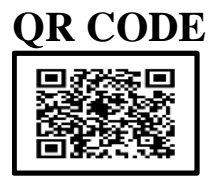

\section{SANTOSH AGARWAL', NEHA JAJODIA², SUBHA LAKSMI³, PRIYA KANDPAL ${ }^{4}$}

Idiopathic thrombocytopenic purpura (ITP) is an anomalous decrease in the number of platelets with obscure etiologic causes. Clinical signs primarily include muco-cutaneous i.e. Petechia, purpura, ecchymosis. The most important aspects of management in this disease, is to anticipate, and control bleeding hence preventing any life threatening consequences. Transfusion of platelets, steroid therapy, Anti-D immunoglobulin are the main stay of treatment. Thrombopoietin receptor agonists and splenectomy may be necessary in some severe cases. We report a case of a young girl with ITP, identified at our unit. She was admitted to the hospital for observation and was successfully treated with steroids therapy.

KEYWORDS: Idiopathic Thrombocytopenic Purpura, Thrombocytopenic Purpura, Platelets

\section{INTRODUCTION}

Oral and maxillofacial surgeons routinely come across a wide variety of medically compromised patients in daily practice. Patients with haemorrhagic disorders are amongst the most challenging to treat. Intra or postoperative bleeding can contribute to life threatening complications in even the simplest surgical procedures. ${ }^{1}$ In spite of the fact that the prevalence of bleeding disorders in patients treated by dental and oral surgery specialists is low, it was reported that $2.3 \%$ of 1,500 adult patients in a dental school had bleeding problems making it way more prevalent than cancer, renal disorders, or joint replacement. ${ }^{2}$

Idiopathic thrombocytopenic purpura (ITP) is one such haemorrhagic condition with obscure etiologic causes. In this condition, altered platelet number manifests in the form of a hemorrhagic disorder. It is an acquired autoimmune disease identified by mild to severe thrombocytopenia. It is primarily characterized by muco-cutaneous bleeding, petechia, purpura, ecchymosis with the absence of other abnormalities. ${ }^{3}$

Diagnosis is usually by exclusion of other possible causes such as errors in lab report, infections and drug or medication interaction. ${ }^{1}$

Platelets play a fundamental role in the blood clotting system. They participate in the initial phase of the haemostatic process by adhering to the collagen and aggregating to form the clot/plug. Later, during coagulation itself, platelets continue to exert an important function for the release of platelet factor 3, to facilitate the interaction of diverse factors of coagulation. ${ }^{4}$ Platelets are a critical component in the haemostatic system. Pathologic processes that perturb/ impair platelet function can have untoward effects on the process of haemostasis.

The purpose of this article is to discuss the case of a young patient who presented with such a platelet disorder and was successfully managed in the maxillofacial ward.

\section{CASE REPORT}

A four year old girl presented to the department of Oral and Maxillofacial Surgery with a complaint of bleeding from mouth and swelling over the face following a self-fall at her residence [Figure 1(a)]. Extra-orally, patient had developed a hematoma over the chin region depicted by dark bluish discoloration of skin and swelling of size $2 X_{3} \mathrm{~cm}$ at its greatest dimension [Figure $1(\mathrm{~b})$ ]. On intraoral examination she had ecchymosis over the right buccal mucosa, right lower buccal and labial vestibule and floor of mouth. There was a continuous ooze of blood noted at right lower vestibule. (Figure 1c). The patient's dentition was otherwise in a satisfactory condition. On further examination, petechiaes and discoloration of the skin were seen throughout the body, especially over the lower limbs (Figure2), but the patient was not aware of these discolorations.

Hepatomegaly, splenomegaly and lymphadenopathy were absent. The patient's medical history was otherwise unremarkable. The 
medical history revealed that the patient did not have any systemic disease and had never presented with any bleeding/ hemorrhage related problem prior to this. However, patient did give history of fever a month back. She had no allergies and was not taking any medications. Patient's blood was sent to test for various haematological parameters. Meanwhile, mandibular occlusal and Orthopantamogram radiographs were taken. This did not reveal any bony fracture thus giving a clear picture of soft tissue hematoma secondary to selffall. Reports revealed a low platelet number of 11,00o. RBC was 3.46 million/cumm, $\mathrm{Hb}$ as 9.3 $\mathrm{gm} / \mathrm{dl}$. Her Prothrombin time was 16 seconds, activated partial thromboplastin time was 33.6 seconds and other hematologic test results were within normal limit. The patient was admitted in our ward for further management.

Paediatric and haematology consultations were taken to rule out any other blood dyscracias or pathology. Patient was primarily treated with I.V Methylprednisolone $30 \mathrm{mg} / \mathrm{kg}$ OD and $500 \mathrm{mg}$ in $500 \mathrm{ml}$ Normal saline HS for 3 days, supplemented with I.M Vitamin K romg OD. Supportive treatment like analgesic and anti-gastritis was given in form of I.V Rantac $2 \mathrm{mg}$ OD and Tablet Combiflam for 3 days. Patient was advised not to brush her teeth as a precautionary measures to avoid any further trauma to the site of hematoma. Oral hygiene was maintained by thorough irrigation with $0.2 \%$ chlorohexidine and normal saline.

The next day; following the administration of cortisone, the platelet count did not differ compared to baseline: Platelet count increased from 11,000 to 12,00o. After 5 days new haematological examinations were done revealing increase in platelet count from 11,000 to 1.28 lakhs.From here on the patient speedily recovered without further problems. Both extra-oral and introral hematoma showed the sign of gradual resolution with reduction in size and fading of color of hematoma. The petechias diminished and ultimately disappeared, and the recovery of spontaneous hemorrhage was observed. The patient was motivated to practice regular tooth brushing with a soft-bristle toothbrush and $0.2 \%$ chlorhexidine digluconate oral rinse was prescribed.
At 2 months follow up, the patient was found to be symptom free (Figure 3,4).

\section{DISCUSSION}

Idiopathic Thrombocytopenic Purpura(ITP) is a rare haematologic disorder widely diagnosed by exclusion of other diseases based on history, physical findings, complete blood count with peripheral smears and coagulation studies. ${ }^{5}$ Mucocutaneous bleeds presenting as petechiae, ecchymosis, haematoma etc along with epistaxis, melena are common findings. Ruling out errors in lab findings, infections, coagulation altering drug/medication history may direct towards a diagnosis of ITP. ${ }^{6}$

The clinical presentation of ITP can be asymptomatic, but careful physical examination can reveal tell-tale signs of a haematologic disorder. Signs can range from small petechiae, mild skin and mucus bleeding, ecchymois to intense and serious blood loss to the point of threatening life. ITP can occur at any age, but it is more common in children and adolescents. Incidence of ITP ranges from 1 to 13 per 100,000 persons. ${ }^{7}$ ITP can present in two clinical forms, an acute self-limiting form exclusively seen in children and a chronic form more common in adult population. Acute ITP has a peak incidence in 3-5 year old children without gender prediliction. ${ }^{5}$

Our patient too was a 4 year old girl, presenting with the acute form with severe thrombocytopenia. Some authors state that in children, this form of platelet disturbance commonly appears after a viral infection and disappears without any type of treatment after some weeks or months. ${ }^{8}$ In our patient too, a history of fever in the preceding month, can be suggestive of a viral infection.

In her blood reports, severe thrombocytopenia was reported in the first CBC $(11,000 / \mathrm{mm})$. Hence, it was decided that the patient should be referred to a hematologist for appropriate consultation. Since the patient required no active surgical intervention, and there were no progressive symptoms, it was decided not to transfuse platelets inspite of the low platelet levels. Patient was kept on close observation and was administered corticosteroids (IV methyl 
prednisolone), Vitamin K, and analgesics.

At present, Corticosteroids (ie, oral prednisone, intravenous [IV] methylprednisolone, or highdose dexamethasone) are the main drugs of choice for the initial management of acute ITP. Corticosteroid administration may result in reduced rate of platelet destruction with rapid alteration of endothelial cell integrity to facilitate primary hemostasis and reduce episodes of bleeding and bruising. ${ }^{9,10}$

Repeat blood tests in intervals (Table 1) showed progressive improvement in platelet levels with dramatic improvement at 5 th day. For cases which do not respond to this management, various options for the treatment of ITP may be suggested by the haematologist especially in case where surgical procedures are planned. ${ }^{11}$

\section{CONCLUSION}

Although a rare clinical condition, an oral physician may encounter a patient of Idiopathic Thrombocytopenic Purpura in the dental clinic/ hospital. It is generally a benign condition, but can turn life threatening if proper history is not elicited. The importance of proper history, examination and pertinent investigations for an early diagnosis cannot be over emphasized, if complications of grave nature are to be avoided. Necessary precautionary measures need to be meticulously taken care of.

\section{REFERENCES}

1. Ahmed M, Martinez AY. Idiopathic Thrombocytopenic Purpura (ITP) Topic Review and Case Report. Int J Oral Craniofac Sci. 2017;3(1): oo8-o11.

2. Patton LL, Ship JA: Treatment of patients with bleeding disorders. Dent Clin North Am. 1994;38(3):465-82.

3. Shan NN, Zhu SJ, Peng J, Qin P, Zhuang XW, Wang HC, et al. Interleukin 18 and inter-leukin 18 Binding protein in patients with idiopathic Thrombocytopenic purpura. $\mathrm{Br} \mathrm{J}$ Haematol 2009;144(5):755-61.
4. Guyton AC, Hall JE. Tratado de fisiologia médica. 1oa ed. Rio de Janeiro: GuanabaraKoogan; 2002.

5. Sunita M, Rajesh R. Idiopathic Thrombocytopenic Purpura. Overview with Report of a Case. Journal of Indian Academy of Oral Medicine and Radiology 2011;23:S454-S457.

6. Provan D, Newland A. Fifty years of idiopathic thrombocytopenic purpura management of refractory ITP in adults. $\mathrm{Br} \mathrm{J}$ Haematol 2002;118(4):933-44.

7. George JN, El-Harake MA, Aster RH. Thrombocytopenia due to enhanced platDent Clin North Am. 1994;38(3):465-82.elet destruction by immune mechanisms. McGraw Hill, New York; 1996 (p. 1315-1355).

8. Martins G, Rozas FG, de Oliveira Ribas M, et al. Idiopathic thrombocytopenic purpura and oral surgery: case report. Rev Clín Pesq Odontol 2010 jan/apr; 6:87-93.

9. Cheng Y, Wong R, Soo Y, Chui C, Lau F, Chan N et al. Initial Treatment of Immune Thrombocytopenic Purpura with High-Dose Dexamethasone. N Engl J Med 2003;349(9):831-36. 10. Immune Thrombocytopenic Purpura (ITP) Treatment \& Management: Medical Care, Surgical Care, Consultations [Internet]. Emedicine.medscape.com. 2017 [cited 12 December 2017]. Available from: https://emedicine.medscape.com/article/202158treatment

11. Gernsheimer T. Chronic idiopatic thrombocytopenic púrpura: mechanisms of pathogenesis. Oncologist. 2009;14(1):12-21. 
Source of support: Nil, Conflict of interest: None declared
Cite this article as:

Agarwal S, Jajodia N, Laksmi S, Kandpal P. Idiopathic Thrombocytopenic Purpura (ITP): A Case Report. Int Healthcare Res J 2018;1(10):315-319.

\section{AUTHOR AFFILIATIONS:}

MDS (Oral and Maxillofacial Surgery), Fellow Trauma, Department of Oral and Maxillofacial Surgery, Postgraduate Institute of Dental Sciences, Rohtak MDS (Oral and Maxillofacial Surgery), Independent Researcher

MDS (Oral and maxillofacial surgery), Professor, Department of Oral and Maxillofacial Surgery, College of Dental Sciences, Davanagere

4. MDS (Oral and Maxillofacial Surgery), Independent Researcher.

\section{Corresponding Author:}

\section{Dr Neha Jajodia}

MDS (Oral and Maxillofacial Surgery)

Ex-fellow (Postgraduate Institute of Dental Sciences

Rohtak) and Independent Researcher

Kolkata, India

For article enquiry/author contact details, e-mail at:

manuscriptenquiry.ihri@gmail.com

\section{LEGENDS}

\begin{tabular}{|c|c|c|c|c|}
\hline TESTS & ON ADMISSION & 24 HRS & $5^{\mathrm{TH}} \mathrm{DAY}$ & AT 2 WEEKS \\
\hline PLATELET & 11,000 /cumm & 12,000 /cumm & $\begin{array}{c}1.28 \\
\text { lakhs/cumm }\end{array}$ & $\begin{array}{c}5.12 \\
\text { lakhs/cumm }\end{array}$ \\
\hline $\mathbf{R B C}$ & 3.46 million/cumm & 3.4 million/cumm & 3.6 million/cumm & 3.5 million/cumm \\
\hline HB & $9.3 \mathrm{gm} / \mathrm{dl}$ & $9.3 \mathrm{gm} / \mathrm{dl}$ & $10 \mathrm{gm} / \mathrm{dl}$ & $9.3 \mathrm{gm} / \mathrm{dl}$ \\
\hline HEMATOCRITE & $28.4 \%$ & $27.3 \%$ & $30.4 \%$ & $30.3 \%$ \\
\hline $\mathrm{WBC}$ & 7300 cells/cumm & 966ocells/cumm & 1518ocells/cumm & 1898ocells/cumm \\
\hline PROTHROMBIN TIME & $16 \mathrm{sec}$ & - & - & - \\
\hline $\begin{array}{l}\text { ACTIVATED PARTIAL } \\
\text { PROTHROMBIN TIME }\end{array}$ & $33.6 \mathrm{sec}$ & - & - & - \\
\hline
\end{tabular}

Table 1. Blood parameters of the patient

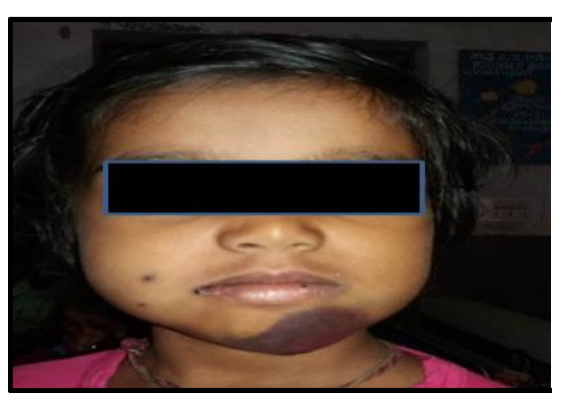

Figure 1(a). Patient reporting to the OPD Clinic

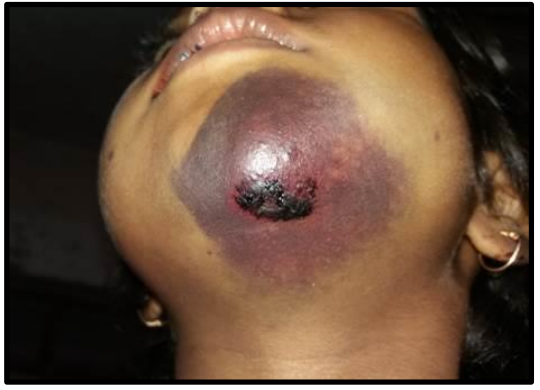

Figure 1(b). Hematoma over the chin region with swelling of size $2 X_{3} \mathrm{~cm}$

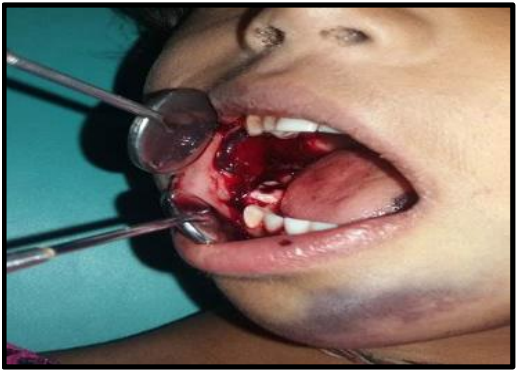

Figure 1(c). Continuous ooze of blood noted at right lower vestibule 


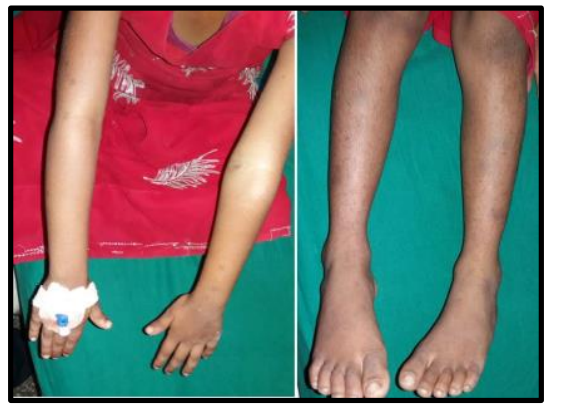

Figure 2. Petechiaes and discoloration of the skin especially the lower limbs

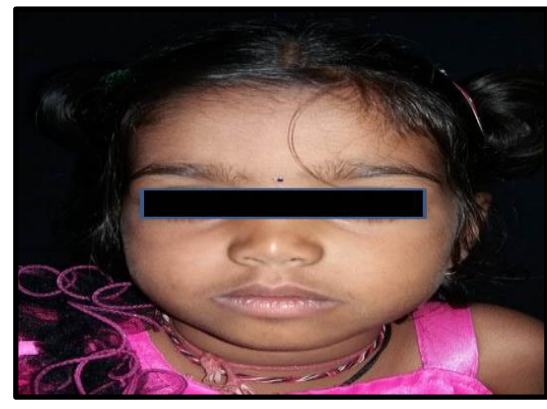

Figure 3. Follow up of the patient after 2 months

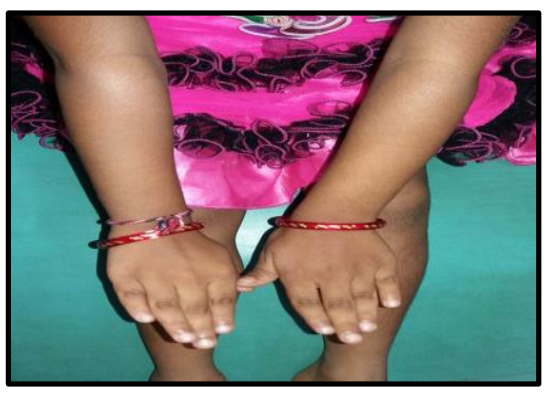

Figure 4. Follow up of the patient after 2 months 